\title{
Analisis Unsur Intrinsik Naskah Drama Pinangan Karya Anton Checkov Saduran Suyatna Anirun
}

\author{
Krisma Jayanti, Budi Dharma, Arni Apriani \\ Jurusan Seni Drama Tari dan Musik \\ Fakultas Keguruan dan Ilmu Pendidikan, Universitas Muhammadiyah Tasikmalaya \\ Jl. Tamansari No.KM2,5 Mulyasari, Tasikmalaya, Jawa Barat 46196 \\ Krismajayanti34@gmail.com
}

\begin{abstract}
ABSTRAK
Krisma jayanti, 2021. Analisis Unsur Intrinsik Naskah Drama Pinangan Karya Anton Checkov Saduran Suyatna Anirun. Skripsi, Fakultas Keguruan dan Ilmu Pendidikan, Universitas Muhammadiyah Tasikmalaya. Tujuan Penelitian ini adalah mendeskripsikan unsur intrinsik Naskah drama Pinangan Karya Anton Checkov Saduran Suyatna Anirun. Sumber data penelitian ini adalah Naskah drama Pinangan Karya Anton Checkov saduran Suyatna Anirun sebagai data Primer dengan Studi pustaka beberapa jurnal dan sumber lainya. Metode penelitian yang penulis gunakan adalah metode kualitatif dengan menggunakan teknik deskriptif analisis dengan penedekatan objektif melalui analisis struktural. Hasil penelitian dari naskah drama yang berjudul "Pinangan" Karya Anton Checkov Saduran Suyatna Anirun terbagi menjadi dua aspek yaitu unsur intrinsik dan beberapa penggunaan gaya bahasa. Unsur intrinsik diantaranya tema, tokoh dan penokohan, alur, latar, dan dialog. Tema yang didapat yaitu bercerita tentang Pinangan. Tokoh dan penokohan yaitu Agus seorang tuan muda yang berpenyakitan berniat baik akan melamar Ratna. Tokoh Ratna seorang perawan tua putri tunggal Rukmana. Tokoh Rukmana Kholil Saudagar tanah kaya raya. Alur yang digunakan yaitu alur maju. Latar di ruang tamu rumah Rukmana Kholil. Dan dialog dari ke tiga tokoh sebagai jembatan untuk mengungkapkan cerita. Gaya bahasa yang digunakan terbagi menjadi dua jenis yaitu perbandingan dan penegasan. Majas perbandingan diantaranya hiperbola, personifikasi, defersonifikasi, litotes, simbolik. Dan majas penegasan yaitu klimaks.
\end{abstract}

Kata Kunci : Unsur Intrinsik, Naskah Drama, Pinangan.

\section{ABSTRACT}

Krisma Jayanti, 2021. Analysis of the Intrinsic Elements of the Drama Script by Anton Checkov Saduran Suyatna Anirun. Thesis, Faculty of Teacher Training and Education, University of Muhammadiyah Tasikmalaya. The purpose of this study is to describe the intrinsic elements of the drama script Pinangan by Anton Checkov Saduran Suyatna Anirun. The data sources of this research are the drama script Pinangan by Anton Checkov, adaptation of Suyatna Anirun as primary data and literature studies of several journals and other sources. The research method that the author uses is a qualitative method using descriptive analysis techniques with an objective approach through structural analysis. The results of the research from the drama script entitled "Pinangan" by Anton Checkov Saduran Suyatna Anirun are divided into two aspects, namely intrinsic elements and some use of language styles. Intrinsic elements include themes, characters and characterizations, plot, setting, and dialogue. The theme obtained is telling stories about Pinangan. The character and characterization, Agus, a young master who is ill with good intentions, will propose to Ratna. Ratna's character is a spinster, the only daughter of Rukmana. Rukmana Kholil is a rich land merchant. The flow used is the forward flow. Background in the living room of Rukmana Kholil's house. And the dialogue of the three characters as a bridge to reveal the story. The style of language used is divided into two types, namely comparison and affirmation. Comparative figures of speech include hyperbole, personification, defersonification, litotes, symbolic. And the figure of speech of affirmation is the climax.

Keywords: Intrinsic Element, Drama Script, Proposal.

\section{A. Pendahuluan}

Karya sastra adalah suatu kegiatan kreatif sebuah karya seni yang ditulis dan tercetak. Karya sastra sebagai hasil karya imajinatif pengarang dapat berfungsi sebagai hiburan yang menyenangkan,

menambah pengalaman batin dan juga dapat mendidik. Sejalan dengan pendapat tersebut Horatius (dalam Wellek dan Warren, 1989: 25) mengungkapkan bahwa secara umum karya sastra mempunyai dua manfaat 
atau fungsi utama yaitu dulce et utile. Dulce berarti sangat menyenangkan atau kenikmatan, sedangkan utile berarti isinya bersifat mendidik.

Karya sastra sebagai hiburan, pendidikan, dan sebagai gambaran kondisi masyarakat ini, memiliki berbagai jenis atau genre seperti yang diungkapkan oleh Aristoteles dalam (Teeuw, 1984: 85), "genre karya sastra dibagi berdasarkan ragam perwujudannya (manner of poetic reprsentation ) terdiri atas tiga macam, yaitu epik (prosa), lirik (puisi), dan drama".

Pembicaraan tentang drama yang muncul di tengah masyarakat lebih banyak terfokus pada pementasan atau seni pertunjukannya dan terkadang lupa bahwa drama merupakan sebuah karya sastra. Padahal, sesungguhnya drama mempunyai dua dimensi, seperti yang diungkapkan oleh Hasanudin (1996: 1), "drama sebagai suatu karya yang mempunyai dua dimensi karakter, yaitu sebagai genre sastra dan sebagai seni lakon, seni peran atau seni pertunjukan". Sebagai dimensi sastra pengertian drama lebih ditekankan pada naskah yang ditulis dalam bentuk dialog, yang dapat dinikmati, dimengerti, dan dipahami dengan cara membacanya. Sebagai seni pertunjukan drama dibangun melalui unsur-unsur pembangun karya seni pertunjukan yang di dalamnya terdapat beberapa karya seni lainnya seperti seni gerak, seni tari, seni vokal, seni musik, seni rupa, dan lainnya. Jadi sebenarnya drama juga merupakan bagian dari genre sastra dan merupakan karya sastra jika dalam bentuk teks.

Sebagai karya sastra, drama dibangun oleh unsur-unsur pembangun yaitu unsur intrinsik dan unsur ektrinsik. Untuk menghubungkan keterkaitan antar unsur tersebut diperlukan adanya sebuah analisis struktural, yang pada dasarnya analisis ini dilakukan dengan mengidentifikasi, mengkaji, dan mendeskripsikan fungsi dan hubungan antarunsur intrinsik dalam karya sastra yang bersangkutan.

Naskah drama yang penulis analisis adalah naskah drama yang berjudul "Pinangan". Naskah drama tersebut penulis pilih karena naskah drama ini pernah memenangkan penghargaan Pushkin pada Tahun 1886. Penghargaan tersebut menandai awal karir Anton Checkov yang sangat produktif sebagai pengarang. Sebetulnya naskah ini berasal dari bahasa Rusia yang berjudul The Proposal, kemudian disadur oleh Suyatna Anirun dengan Judul naskah drama yang berubah menjadi Pinangan. Selanjutnya penulis memilih naskah drama Pinangan Karya Anton Checkov sebab berdasarkan sepengetahuan penulis, naskah drama ini belum banyak diteliti sebelumnya sehingga penulis menggunakan naskah drama ini sebagai bahan penelitian.

Dalam penelitian ini, mengkaji tentang struktur yaitu unsur intrinsik naska drama. Tinjauan terhadap analisis unsur intrinsik naskah drama dilakukan untuk memperoleh pemahaman yang lengkap mengenai sebuah lakon baik secara naskah dan pemanggungan. Selain itu untuk mempermudah pembaca dalam memahami pesan yang disampaikan pada naskah drama. Setiap naskah drama menyuguhkan narasi yang berisi pesan pada drama. Untuk menyempurnakan naskah drama menjadi layak untuk dipublikasikan ke pembaca, sehingga pembaca dapat menerima informasi yang bermutu dari naskah tersebut.

Penelitian ini penulis mengkaji naskah drama menggunakan teknik deskriptif analisis dengan metode kualitatif melalui pendekatan objektif dengan analisis struktural. Penelitian ini penulis ajukan dalam bentuk skripsi yang berjudul "Analisis Unsur Intrinsik Naskah 
Drama Pinangan Karya Anton Checkov Saduran Suyatna Anirun".

\section{B. Metode Penelitian}

1. Jenis Penelitian

Jenis penelitian yang digunakan dalam penelitan ini adalah penelitian kualitatif. Penelitian kualitatif ialah yang lebih mementingkan proses dari pada produk, karena proses terjadinya sesuatu itu lebih penting daripada adanya sesuatu tersebut.

Peneliti ingin mengetahui unsur intrinsik naskah drama Pinangan karya Anton Checkov Saduran Suyatna Anirun. Maka langkah awal yang akan dilakukan peneliti adalah melakukan studi pustaka dengan mengumpulkan data primer yaitu Naskah Drama Pinangan Karya Anton Checkov Saduran Suyatna Anirun, dan data sekunder beberapa buku, jurnal dan sumber lainya. Kemudian menganalisis dengan teknik analisis wacana dan menyimpulkan hasil analisis unsur intrinsik naskah drama Pinangan Karya Anton Checkov Saduran Suyatna Anirun.

\section{Data dan Sumber data}

Sumber data adalah segala sesuatu yang mampu menghasilkan atau memberikan data atau menunjuk pada tempat. Sumber data yang di pilih berdasarkan jenis informasi yang di perlukan berdasarkan arahan beragam hal yang terdapat dalal rumusan masalah. (Sutopo,2002:143). Adapun yang menjadi sumber data dalam penelitian ini adalah naskah drama pinangan karya Anton Checkov saduran Suyatna Anirun.

Sumber data dalam penelitian ini adalah naskah drama Pinangan karya Anton Chekov saduran Suyatna Anirun. Identitas naskah drama yang menjadi sumber data dalam penelitian ini adalah sebagai berikut.

$$
\text { Judul : : Pinangan }
$$

\begin{tabular}{|c|c|c|}
\hline Pengarang & : & Anthon \\
\hline Asal Naskah & : Rusia & \\
\hline $\begin{array}{l}\text { Saduran } \\
\text { dan Jim Lim }\end{array}$ & : Suyatna & Anirun \\
\hline Diposkan & : Studio & Teater \\
\hline PPPG Keseni & Yogyakarta & \\
\hline Tahun Terbit & $: 2006$ & \\
\hline Jumlah Halar & 15: ר & \\
\hline Jenis Buku & Fik & /Naskah \\
\hline
\end{tabular}

\section{Hasil Dan Pembahasan}

1. Hasil

Hasil penelitian yang diperoleh adalah memaparkan struktur atau unsur intrinsik naskah drama "Pinangan" karya Anton Checkov saduran Suyatna Anirun. Hasil pembahasan akan diuraikan menjadi beberapa bagian. Bagian pertama yaitu mendeskrepsikan tema, tokoh dan penokohan, alur, latar dan dialog pada naskah drama "Pinangan" karya Anton Checkov saduran Suyatna Anirun. Bagian kedua mendeskrepsikan jenis gaya bahasa yang terdapat pada naskah drama "Pinangan" karya Anton Checkov saduran Suyatna Anirun.

Struktur atau unsur intrinsik menjadi penghubung antara satu unsur dengan unsur yang lain. hubungan tersebut tidak semata-mata bersifat positif, seperti keselarasan, kesesuaian, dan kesepahaman, tetapi juga negatif, seperti konflik dan pertentangan. Struktur yang terdapat dalam drama ada alur, tokoh dan penokohan, tema, latar, amanat, gaya bahasa dan setting. Peneliti hanya mengambil enam bagian saja untuk dianalisis pada naskah drama "Pinangan" dalam penelitian. struktur yang akan dianalisis yaitu tema, tokoh dan penokohan, alur, latar, dialog dan gaya bahasa.

\section{Pembahasan}


Unsur intrinsik dalam naskah drama Pinangan karya Anton Checkov saduran Suyatna Anirun dan yang akan dibahas pada sub-bab ini meliputi tema, tokoh dan penokohan, alur, latar, dialog dan gaya bahasa yang terdapat dalam naskah drama Pinangan Karya Anton Checkov saduran Suyatna Anirun.

\section{a. Tema}

Di dalam naskah ini pengarang menyuguhkan sebuah cerita drama komedi satu babak yang mengisahkan tentang Agus Tubagus yang ingin meminang putri dari Rukmana Kholil awalnya keinginan dari agus untuk meminang putri rukmana disambut gembira oleh rukmana namun, setelah kemunculan ratna dalam naskah suasana menjadi memanas dan akhirnya berubah menjadi pertikaian yang menyebabkan kesalahpahaman sehingga niat agus untuk melamar ratna diurungkan karena agus diusir oleh ratna hanya karena perselisihan hak milik dari lapangan Sari gading. Sekilas tentang cerita yang sudah dipaparkan diatas maka sesuai dengan isi cerita maka peneliti dapat menyimpulkan bahwa temanya adalah "Pinangan" yang mana dalam artian yang lain pinangan berarti lamaran, niat atau keinginan dari pihak laki-laki untuk meminta kepada orang tua perempuan untuk merestui atau meminta izin untuk menikahi anaknya.

\section{b. Tokoh dan Penokohan}

Di dalam naskah pinangan ini yang menjadi tokoh sentralnya hanya berjumlah tiga orang saja, yaitu Agus tubagus, Ratna dan Rukmana Kholil. Dalam penokohan dikenal ada tiga jenis penokohan yaitu: Tokoh protagonis atau tokoh yang digemari oleh pembaca karena bersifat baik. Tokoh antagonis tokoh yang pemarah atau bersifat jahat. Dan yang terakhir adalah tokoh tritagonis yang biasanya menjadi penengah didalam permasalahan yang muncul. Didalam naskah pinangan ini semua pemain atau tokoh-tokohnya bersifat netral, kadang bisa baik kadang bisa jadi pemarah, atau biasa juga disebut dengan istilah tokoh bulat yaitu bersifat tidak tetap dan berkembang sesuai dengan jalannya cerita.

Penulis mengambil pembagian jenis tokoh menurut teori dari Satoto tokoh protagonis, tokoh antagonis, tokoh tirtagonis, dan tokoh peran pembantu, dan menurut teori Aminudin yaitu tokoh sederhana dan tokoh bulat.

\section{c. Alur}

Alur yang diguanakan dalam naskah drama pinangan adalah alur maju. Menurut Boulton (dalam Satoto, 2016:50) alur maju (progresive plot), "yaitu jalinan peristiwa dalam suatu karya sastra yang berurutan dan berkesinambungan secara kronologis dari tahap awal sampai tahap akhir cerita (melalui tahap-tahap pemaparan atau perkenalan, penggawatan atau perumitan, klimaks atau puncak, peleraian, dan kemudian penyelsaian)." Tahapan alur dalam drama terdiri atas: eksposisi, komplikasi, klimaks, dan resolusi.

Berikut benjabaran tahapan alur yang membentuk naskah drama Pinangan.

\section{1) Eksposisi}

Eksposisi adalah tahap pengenalan informasi yang berfungsi sebagai pengantar. Pada tahap ini mulai diperkenalkan latar belakang cerita, waktu, tempat, tokoh dan situasi yang akan mengantar pada suatu permasalahan atau konflik yang akan terjadi.

Dalam naskah drama pinangan pengarang mengawali dengan tokoh Rukmana yang sedang duduk bersantai di ruang tamu rumahnya, tiba tiba Agus sebagai tetangga berniat baik bersilaturahmi mengunjungi rumah Rukmana dengan tujuan akan meminang 
Ratna. Agus yang tidak biasanya memakai pakaian rapi dengan jas dan membawa sapu tangan membuat rukmana bertanya tanya kepada Agus.

\section{2) Komplikasi}

Tahap ini adalah ketika peristiwaperistiwa yang menyebabkan konflik bermunculan. Pada naskah drama pinangan ini, ada dua konflik yang muncul, konflik yang menjadi pembahasanya pun berbeda yaitu tentang lapangan Sari Gading dan Hewan peliharaan anjing yang bernama si kliwon dan si belang. Untuk yang pertama mengenai permasalahan lapangan Sari Gading. Agus yang gugup akan menyatakan cintanya terhadap Ratna ketika berbicara masalah harta yang dimiliki agus tentang lapangan Sari gading ratna menolak pernyataan agus mengenai hak milik lapangan Sari gading.

\section{d. Klimaks}

Klimaks adalah bagian alur yang merupakan titik puncak dari segala konflik atau peristiwa-peristiwa yang terjadi sebelumnya. Pada naskah drama ini klimaks terjadi adalah bagian pada ketika Ratna mengetahui bahwa Agus akan meminangnya akan tetapi mereka malah mengusirnya. Disitulah ratna merasa menyesal dengan sikapnya dan meminta Rukmana menyusul dan membujuk Agus supaya ia kembali ke rumahnya. Ratna menangis, karena sangat menyesal dan merasa sangat bersalah kepada Agus.

\section{3) Resolusi}

Resolusi adalah bagian alur yang menjelaskan tentang penyelesaian masalah atau menemukan jalan pemecahan masalah. Bagian resolusi pada naskah drama pinangan ini adalah ketika Rukmana memutuskan kepada Ratna sebagai anaknya dan Agus yang melamarnya untuk segera menikah saja.

\section{e. Latar}

Latar adalah kesatuan ruang dan waktu, seperti yang diungkapkan Semi (1993: 46), “ latar adalah lingkungan tempat peristiwa terjadi, termasuk tempat atau ruang yang diamati". Dalam naskah drama pinangan karya Anton Checkov Saduran Suyatna Anirun latar waktu yang akan dijelaskan berikut ini.

1) Latar Tempat

Latar tempat pada naskah drama pinangan karya Anton Checkov saduran Suyatna Anirun adalah berada pada satu tempat saja yaitu Ruang Tamu Rumah Raden Rukmana. Identitas latar tempat sangat jelas sebeleum ke dialog awal pengarang menulis lattar tempat kejadian. Latar tempat tersebut berlangsung dari awal sampai akhir. Sebab naskah drama pinangan ini merupakan naskah drama komedi satu babak, dimana hanya menggunakan satu lattar tempat saja.

2) Latar Waktu

Latar waktu dalam naskah drama pinangan karya Anton checkov saduran Suyatna Anirun adalah siang hari.

3) Latar Sosial

Latar sosial merupakan lukisan status yang menunjukan hakikat seorang atau beberapa orang tokoh dalam masyarakat yang ada di sekelilingnya, statusnya dalam kehidupan sosialnya dapat digolongkan menurut tingkatannya, seperti latar sosial bawah atau rendah latar sosial menengah, dan latar sosial tinggi. Dalam naskah drama pinangan ini latar sosialnya atau status dalam kehidupan sosialnya Rukmana dapat di golongkan pada tingkat sosial tinggi. Sebab rukmana merupakan tokoh terkenal di daerahnya, saudagar tanah yang kaya raya, dan sering kali orang yang berdatangan ke rumahnya untuk meminjam uang kepada Rukmana. 


\section{f. Dialog}

Dialog dalam drama merupakan unsur penting, karena drama tanpa adanya dialog penonton atau pembaca akan sulit memahami jalan cerita secara utuh. Dengan adanya dialog penonton atau pembaca akan mudah memahami unsur-unsur pembentuk drama anataralain adalah tema, tokoh dan penokohan, alur, latar dan gaya bahasa yang digunakan.

Melalui uraian sebelumnya tentang tema, tokoh, alur, latar dapat dinyatakan bahwa dialog dalam naskah drama pinangan Karya Anton Checkov saduran Suyatna Anirun dialognya komunikatif karena dalam naskah drama ini mengungkapkan tema, tokoh dan alur dengan jelas. Melalui dialog dalam naskah diketahui bahwa naskah drama ini hasil dari saduran atau perubahan serta pencocokan dari bahasa Rusia ke dalam bahasa Indonesia yang mengungkapkan tentang Pinangan, yaitu mengangkat cara mempertahankam prinsip hidup dan hak milik. Dialog dialog yang digunakan dibalut dengan banyolan yang apik. Dialog nya juga menggambarkan percakapan karakter, masing-masing karakter juga dapat ditampilkan dalam dialog. Selain itu dialog juga dapat menunjukkan perbedaan budaya beberapa orang. Misalnya dengan berbagai dialek atau bahasa dialek. Ini juga berfungsi sebagai deskripsi pengaturan dalam sebuah cerita.

\section{g. Gaya Bahasa}

Gaya bahasa atau majas merupakan bentuk gaya bahasa atau sebuah ungkapan untuk mendapatkan suasana dalam sebuah kalimat agar semakin hidup. Mudahnya majas itu menjadi ungkapan yang bisa menghidupkan suatu kalimat. Berdasarkan hasil penelitian yang telah dilakukan pada naskah drama "Pinangan" karya Anton Checkov saduran Suyatna Anirun dapat ditemukan beberapa penggunaan gaya bahasa yaitu majas perbandingan dan majas penegasan. Majas perbandingan diantaranya personifikasi, hiperbola, personifikasi, defersonifikasi, litotes, dan simbolik sedangkan dalam majas penegasan terdapat klimaks.

1) Majas Perbandingan

Majas perbandingan adalah salah satu gaya bahasa yang digunakan untuk menyandingkan atau me mbandingkan suatu objek dengan objek lain melalui proses penyamaan, pelebihan, ataupun penggantian.

2) Majas Penegasan

Majas penegasan adalah salah satu dari jenis majas atau gaya bahasa yang akan diulang suatu kata dengan tujuan untuk menegaskan tentang sesuatu. Penegasan tersebut akan diungkapkan melalui pengulangan kata yang sama akan tetapi ini sangat berbeda dengan maupun kata yang tidak sama, akan tetapi maknanya masih berkaitan.

\section{Kesimpulan}

Berdasarkan hasil penelitian Tentang Analisis Unsur Intrinsik Naskah Drama Pinangan Karya Anton Checkov Saduran Suyatna Anirun :

\section{Unsur intrinsik diantaranya :}

- Tema naskah ini ialah tentang pinangan atau lamaran.

- Tokoh nya ada 3 yaitu Agus sebagai tokoh Protagonis, Ratna Tokoh Antagonis dan Rukamana sebagai tokoh tritagonis. Dan termasuk ke dalam tokoh bulat.

- Alur atau jalan cerita nya alur Maju yg terdiri dari : eksposisi, konflik, klimaks, sampai dengan resolusi atau penyelesaian.

- Latar atau tempat yaitu di sebuah ruangan tamu milik Rukmana Kholil dan berlangsung dari awal sampai akhir. Kemudian Latar waktu siang hari, dan latar 
sosialnya atau status dalam
kehidupan sosialnya dapat di
golongkan pada tingkat sosial
tinggi.
Dialognya komunikatif makadari itu dengan adanya dialog penonton atau pembaca akan mudah memahami unsur-unsur pembentuk drama anataralain adalah tema, tokoh dan penokohan, alur, latar dan gaya bahasa yang digunakan.

2. Gaya bahasa yang terdapat dalam naskah drama "Pinangan" karya
Anton Checkov saduran Suyatna Anirun dapat ditemukan beberapa penggunaan gaya bahasa yaitu Gaya bahasa perbandingan dan Gaya bahasa penegasan. Gaya bahasa perbandingan di antaranya hiperbola, personifikasi, defersonifikasi, litotes, dan simbolik sedangkan dalam Gaya bahasa penegasan hanya terdapat Gaya bahasa klimaks.

\section{Daftar Pustaka}

Hasanuddin, WS. 2015. Drama Karya Dalam Dua Dimensi. Bandung: Angkasa Bandung. Keraf, Gorys. 2008. Diksi dan Gaya Bahasa. Jakarta: PT Gramedia Pustaka Utama.

Satoto, Soediro. 2016. Analisis Drama dan Teater. Yogyakarta: Ombak.

Satoto, Soediro. 2012. Analisis Drama dan Teater Bagian I. Yogyakarta: Penerbit Ombak. Semarang: IKIP Semarang Press.

Waluyo, J.Herman. 2006. Drama Naskah, Pementasan, dan Pengajarannya. Surakarta: UNS Press. 